\title{
Epidemiology of visceral leishmaniasis through spatial analysis, in Belo Horizonte municipality, state of Minas Gerais, Brazil
}

\section{Carina Margonari, Christian Rezende Freitas*, Rosemary Campos Ribeiro*, Ana Clara Mourão Moura*, Marcos Timbó*, Adriano Heckert Gripp**, José Eduardo Pessanha***, Edelberto Santos Dias/ ${ }^{+}$}

\author{
Centro de Pesquisas René Rachou-Fiocruz, Av. Augusto de Lima 1715, 30190-002 Belo Horizonte, MG, Brasil *Departamento \\ de Cartografia, Instituto de Geociências **Departamento de Engenharia de Minas, UFMG, Belo Horizonte, MG, Brasil \\ ***Secretaria Municipal de Saúde de Belo Horizonte, Departamento de Zoonoses, Belo Horizonte, MG, Brasil
}

The geographic information system approach has permitted integration between demographic, socio-economic and environmental data, providing correlation between information from several data banks. In the current work, occurrence of human and canine visceral leishmaniases and insect vectors (Lutzomyia longipalpis) as well as biogeographic information related to 9 areas that comprise the city of Belo Horizonte, Brazil, between April 2001 and March 2002 were correlated and georeferenced. By using this technique it was possible to define concentration loci of canine leishmaniasis in the following regions: East; Northeast; Northwest; West; and Venda Nova. However, as for human leishmaniasis, it was not possible to perform the same analysis. Data analysis has also shown that $84.2 \%$ of the human leishmaniasis cases were related with canine leishmaniasis cases. Concerning biogeographic (altitude, area of vegetation influence, hydrographic, and areas of poverty) analysis, only altitude showed to influence emergence of leishmaniasis cases. A number of 4673 canine leishmaniasis cases and 64 human leishmaniasis cases were georeferenced, of which 67.5 and 71.9\%, respectively, were living between 780 and $880 \mathrm{~m}$ above the sea level. At these same altitudes, a large number of phlebotomine sand flies were collected. Therefore, we suggest control measures for leishmaniasis in the city of Belo Horizonte, giving priority to canine leishmaniasis foci and regions at altitudes between 780 and $880 \mathrm{~m}$.

Key words: leishmaniasis - spatial analysis - geoprocessing - Belo Horizonte - Brazil

In the 1990s, an increasing capacity of data analysis and ease of information accessibility through cheap and simple computational systems was remarkable. Such technology represents a breakthrough in data bank organization, mainly regarding health.

Geoprocessing is a broad term that is applied to several technologies of manipulation and processing of geographical data through computational programs. System of geographical information (SGI) is one of the geoprocessing techniques, the most widely used, once it gathers organized data at the stages of data capture by remote sensing, GPS or organization of digital cartographic basis, and organizes systems, which are able to obtain new information and improve knowledge. SGI comprises computational systems used for understanding facts and phenomena that occur in the geographical space. Its capacity of gathering data sets of conventional spatial expression, structuring and integrating them adequately, makes it an essential tool for manipulating geographical information (Pina 1994).

Applications of SGI in the field of health have been reported in studies on epidemiological surveys, health

Financial support: Centro de Pesquisas René Rachou-Fiocruz, Fapemig (CBB-2761/98)

+Corresponding author: edel@cpqrr.fiocruz.br

Received 20 July 2005

Accepted 27 December 2005 service assessment, urbanization, and environment. Moreover, evaluation of endemic diseases from the perspective of several elements involved in the transmission cycle, such as historical, environmental, and social determinants of disease foci, became easier with Geoprocessing techniques (Sabroza et al. 1992, Albuquerque 1993, Thomson \& Connor 2000).

Geoprocessing technology has enabled scientists to map vectors and analyze environmental factors that affect spatial and temporal distribution of insects. Such techniques have been used to monitor diseases such as malaria, trypanosomiasis, and leishmaniases (Elnaiem et al. 1998, 2003, Thomson \& Connor 2000).

American cutaneous leishmaniasis (ACL) and visceral leishmaniasis (VL) have been studied through geoprocessing techniques by several investigators: Cross et al. (1996), by gathering data from 136 scientific papers, have generated a distribution model of Phlebotomus papatasi in Southeast Asia throughout the year. By using satellite images and field-collected data in Sudan, Elnaiem et al. (1998, 2003) and Thomson et al. (1999) observed that several ecological factors are crucial for the presence of Phlebotomus orientalis, the vector of VL in that country. Kawa and Sabroza (2002) and Werneck and Maguire (2002) have analyzed historical and spatial determinants, in the city of Rio de Janeiro, Brazil, and Teresina, state of Piauí, Brazil, respectively, for implementation, maintenance, and spread of ACL and their correlation with urban organization and occupation in the periphery of those cities. Hay et al. (1997), Connor et al. (1998), and King et al. (2004) reported 
the use of monitoring techniques through satellites in studies on vectors, which has enabled a detailed description of the actual situation of diseases related to space and time. A study by Oliveira et al. (2001) on VL in the city of Belo Horizonte, state of Minas Gerais, Brazil, revealed the spatial distribution of the disease after georeferencing 11,048 positive dogs and 158 human cases between 1994 and 1997. The author observed that the human cases of the city happened in areas with density of leishmaniasispositive dog relatively high.

Therefore, data collection through geoprocessing techniques has contributed to monitor and specially to identify effective and priority control measures for tropical diseases. The present work aims to provide clarification on visceral leishmaniasis in the city of Belo Horizonte, and give subsidies for the central organs of the state in order to promote improvements to the disease control plans.

\section{MATERIALS AND METHODS}

Georeference - The cartographic basis of Belo Horizonte (maps), used in the present study, were provided by the Department of Zoonosis of the Municipal Secretary of Health of Belo Horizonte (MSHBH) and by the Integrated Program of Geoprocessing Technology from the central organs of the state of Minas Gerais (GeoMinas). All cartographic bases were converted to the terrestrial bearings system SAD 69.

Georeference, based on tabular data related to canine and human leishmaniasis cases (data that provides descriptive information of the graphic aspects), was handmade on the maps under study. Sites of phlebotomine sand fly collection were georeferenced with GPS (global positioning system) through which bearings were got at the moment the field was visited. An indexer (a numeric geoencoder) was used in order to allow us to associate information between tabular data and maps.

Georeference of canine leishmaniasis cases - The georeferenced sample showed positive serological diagnosis, through indirect immunofluorescence for leishmaniasis, performed in the laboratory of the city hall of Belo Horizonte. After leishmaniasis diagnosis had been confirmed, epidemiological bulletins on the dogs' data were issued, including complete address of the case occurrence. Such information was digitalized in the Zoonosis data bank of MSHBH.

From April 2001 to March 2002, a number of $5253 \mathrm{dogs}$ were listed in the data bank of seropositive dogs of MSHBH. Such data access has also allowed us to exclude bulletins of different dogs from the same residence, viz only one leishmaniasis-positive dog from each domicile was georeferenced. Through each residence address, dogs were georeferenced one by one in a cartographic basis of the city of Belo Horizonte, using the software MicroStation 95. By using the geoencoder, dogs identified on the map were recognized in tabular data.

Georeference of leishmaniasis human cases - The number of 64 VL human cases was listed in the data bank of MSHBH in the period between April 2001 and March
2002. Georeference of the cases was undertaken using the same proceedings as those used for canine cases.

Entomological survey - Belo Horizonte comprises nine regions: Barreiro, South-Central, East, Northeast, Northwest, North, West, Pampulha, and Venda Nova. Three residences per area were chosen to have phlebotomine sand flies collected, totaling 27 houses according to Souza et al. (2004).

For sand fly collection two light CDC traps were used (Sudia \& Chamberlain 1962) in each residence, one into the house and the other in the peridomiciliary area. Collections were performed in the last four days of each month throughout the year (from April 2001 to March 2002). Traps were laid at $5 \mathrm{pm}$ and collected at $7 \mathrm{am}$ on the following day. Insects collected each night were killed in chambers with ether and, following, they were placed into labeled hemolysis tubes with $70 \%$ alcohol, and taken to the laboratory. All specimens collected were identified by means of morphological characters, according to the identification key proposed by Young and Duncan (1994).

Entomological maps - The 27 residences under study were georeferenced through GPS and plotted in the map of Belo Horizonte. Buffers (influence areas) of $750 \mathrm{~m}$ around each house on the map were created. Such proceeding enabled visualization of phlebotomine influence based on the flight mean distance of the insects. Afterwards, residences were numbered and correlated in a table containing information on quantity and species of phlebotomine collected at each site. Distribution map of L. longipalpis was drawn by means of summing the insects collected into the houses, included in the study, in each area on the map.

Map of influence of vegetation areas and hydrographic basin - Maps were provided by the Information and Software Company of Belo Horizonte S.A. and by GeoMinas, at the scale of 1:50.0000, respective to 1995 . After the maps georeference, buffers of $30 \mathrm{~m}$ around green regions and areas of water flow were generated through the software ARCVIEW. Afterwards, maps were classified by using the software IDRISI32 for identifying information (presence or absence of vegetation and hydrographic features) through different colors.

Maps of poverty concentration areas - The digitalized map was based on published data by the city hall of Belo Horizonte, in 1995, and organized by Figueiredo et al. (2001). Classification and georeference of the map followed the same procedures as those used for maps of vegetation and hydrographic basins.

Altitude map - Belo Horizonte is between 680 and 1500 $\mathrm{m}$ above the sea level. From a construction of a digital elevation model, colored altimetry stripes were mapped, by using the software IDRISI32. Such classification clustered the altitudes at every $100 \mathrm{~m}$, totaling 9 classes: Class 0: deep (altitudes below $680 \mathrm{~m}$ ); class 1: altitudes between 680 and $780 \mathrm{~m}$; class 2: altitudes between 780 and $880 \mathrm{~m}$; class 3: altitudes between 880 and $980 \mathrm{~m}$; class 4: altitudes between 980 and $1080 \mathrm{~m}$; class 5: altitudes between 1080 and $1180 \mathrm{~m}$; class 6: altitudes between 1180 and $1280 \mathrm{~m}$; 
class 7: altitudes between 1280 and $1380 \mathrm{~m}$; and class 8: altitudes between 1380 and $1480 \mathrm{~m}$.

Analysis of thematic maps - Thematic maps were analyzed jointly by overlapping them. A grid pattern was drawn on all the maps of Belo Horizonte through MapInfo (version 7.0), giving positions of a place within $100 \mathrm{~m}$. Dimensions were determined according to the average size of blocks of the main pathways and the city size (30 $\mathrm{km}$ per $20 \mathrm{~km}$ ). In order to generate projection grids UTM (universal transverse mercator), a rectangle was drawn involving the bearings: 597000 east; 7780000 south; 621000 west; and 7814000 north. Following, the rectangle was divided into 240 columns and 340 lines, generating 816000 cells of 100 per $100 \mathrm{~m}$. This methodology allowed us to perform a vertical analysis of the cells content in all overlapped thematic maps.

Analysis of human and canine leishmaniasis cases After grids were drawn on the maps, counting and classification of the number of cases of the cells were carried out by using MapInfo (version 7.0). Raster-formatted maps were, then, exported to the software IDRISI32. Through this software, an average filter was used aimed at generating a "mobile average" $(3 \times 3$ pixels $)$ on each of the maps.

Maps on the average number of leishmaniasis human and canine cases were classified into four occurrence groups: class 1: absence of leishmaniasis cases; class 2: average of until one leishmaniasis case per pixel; class 3: average of until two cases of leishmaniasis per pixel; and class 4: average of until three cases of leishmaniasis per pixel.

Analysis of the map on canine leishmaniasis cases $X$ map on human leishmaniasis cases - By using the software IDRISI32, the classified maps of canine and human leishmaniasis cases (average numbers) were overlapped. The color-based classification proposed for the overlapping resulting map was: class 0 : absence of human and canine leishmaniasis cases in the same pixel; class: $1 \mathrm{ab}-$ sence of canine leishmaniasis cases and presence of human cases in the same pixel; class 2: presence of canine leishmaniasis cases and absence of human cases in the same pixel; and class 3: presence of canine and human leishmaniasis cases in the same pixel.

Joint analysis of the maps - Georeferenced and classified maps were analyzed using the software SAGA. Such Geo-environmental Analysis System was developed by the laboratory of Geoprocessing of Instituto de Geociências da Universidade Federal do Rio de Janeiro (Institute of Geosciences of the Federal University of Rio de Janeiro) (Silva et al. 1991). This software permits overlapping different maps, corresponding to the several parameters that constitute data bases, aimed at generating risk estimates and environmental potential. Signatures were obtained by overlapping maps and verifying vertical elements of pixels every $100 \mathrm{~m}$ on each map. Such procedures generated reports with the percentages of elements - vegetation, water and poverty - which are present into pixels in relation to the number of canine and human leishmaniasis cases.

\section{RESULTS}

Canine leishmaniasis cases - The data bank provided by the city hall of Belo Horizonte showed 5253 canine leishmaniasis cases between April 2001 and March 2002, of which 4673 were georeferenced (Fig. 1). By obtaining the average number of canine leishmaniasis cases, some foci were observed (areas with more than three canine leishmaniasis cases within $10,000 \mathrm{~m}^{2}-$ a block of $100 \mathrm{~m} \times$ $100 \mathrm{~m}$ ) in the following regions of Belo Horizonte: East, Northeast, Northwest, North, and Venda Nova (Fig. 2).

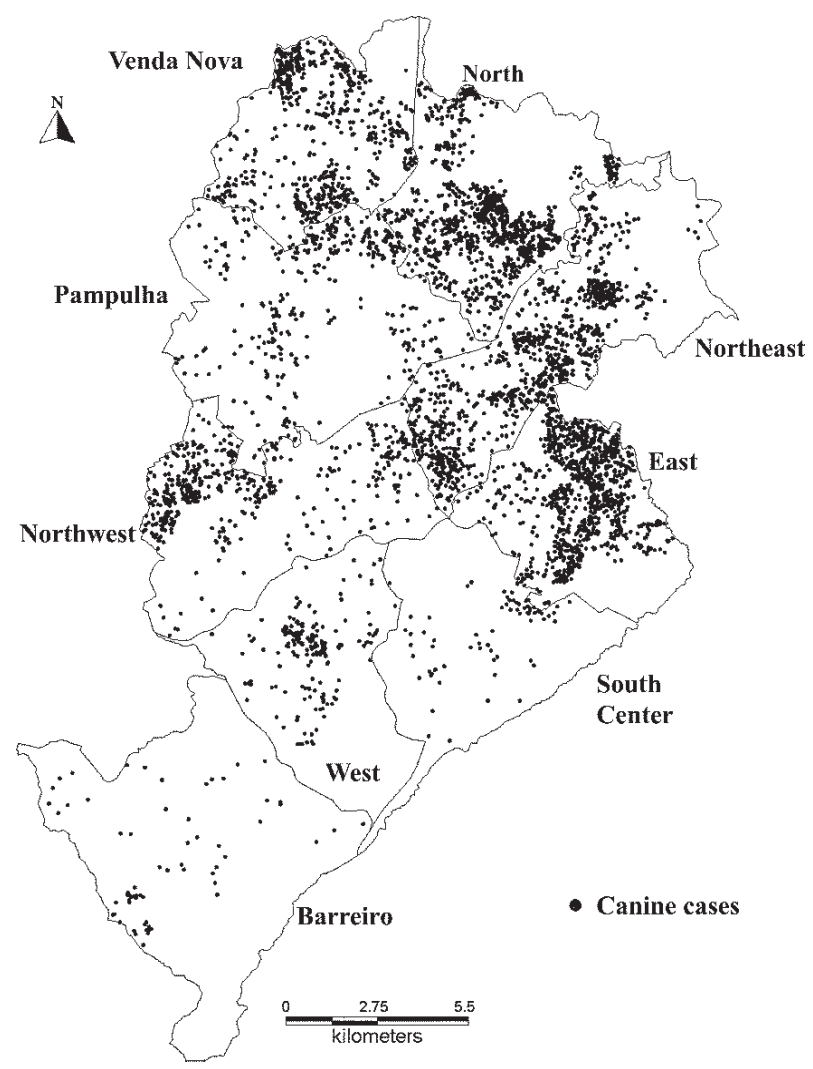

Fig. 1: georefering of canine leishmaniasis cases, which were seropositive through RIFI (performed in the laboratory of the city hall of Belo Horizonte) between April 2001 and March 2002. The software MacroStation was used.

Human leishmaniasis cases - The data bank provided by the city hall of Belo Horizonte showed 64 human VL cases between April 2001 and March 2002. Out of these human cases, two were not georeferenced due to lack of records. The distribution of human cases in Belo Horizonte was determine as follows, according to the regions: no cases in Barreiro; 4 cases the Center-South; 3 cases in the East; 13 cases in the Northeast; 8 cases in Northwest, 13 in the North, 3 in the West, 7 in Pampulha, and 11 in Venda Nova (Fig. 3). Average of human VL cases has shown that they are more concentrated in the following regions: Northeast, Northwest, North, Pampulha, and Venda Nova (Fig. 4).

Dogs cases $X$ human cases - By overlapping maps of average number of canine and human leishmaniasis cases, 

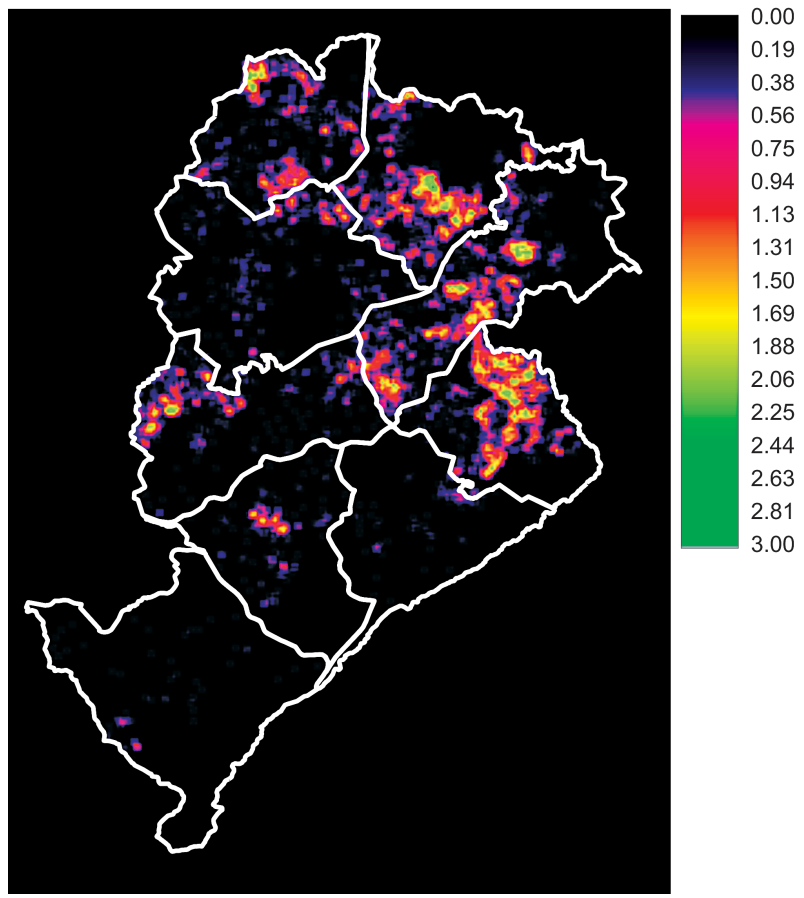

Fig. 2: average of canine leishmaniasis cases between April 2001 and March 2002 in Belo Horizonte, obtained by the filter of mobile average $(3 \times 3$ pixels $)$ of the software IDRISI32.

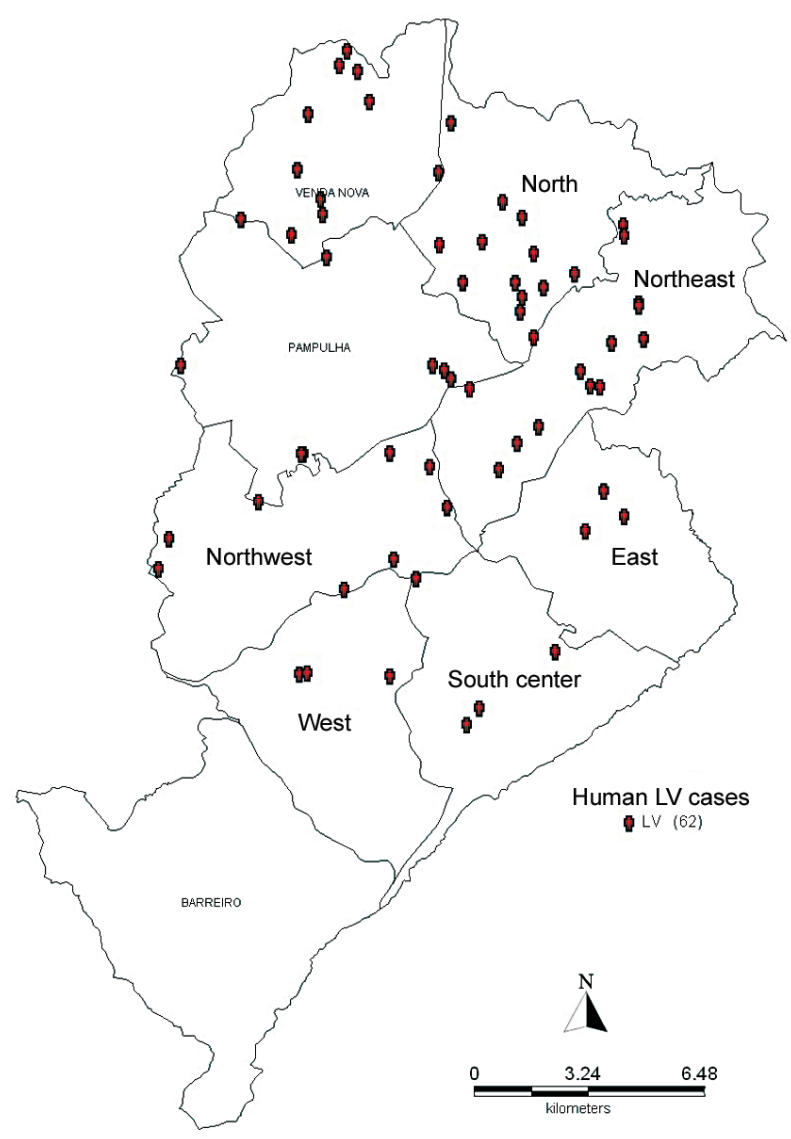

Fig. 3: georefering of human visceral leishmaniasis cases between April 2001 and March 2002. The software MacroStation was used.

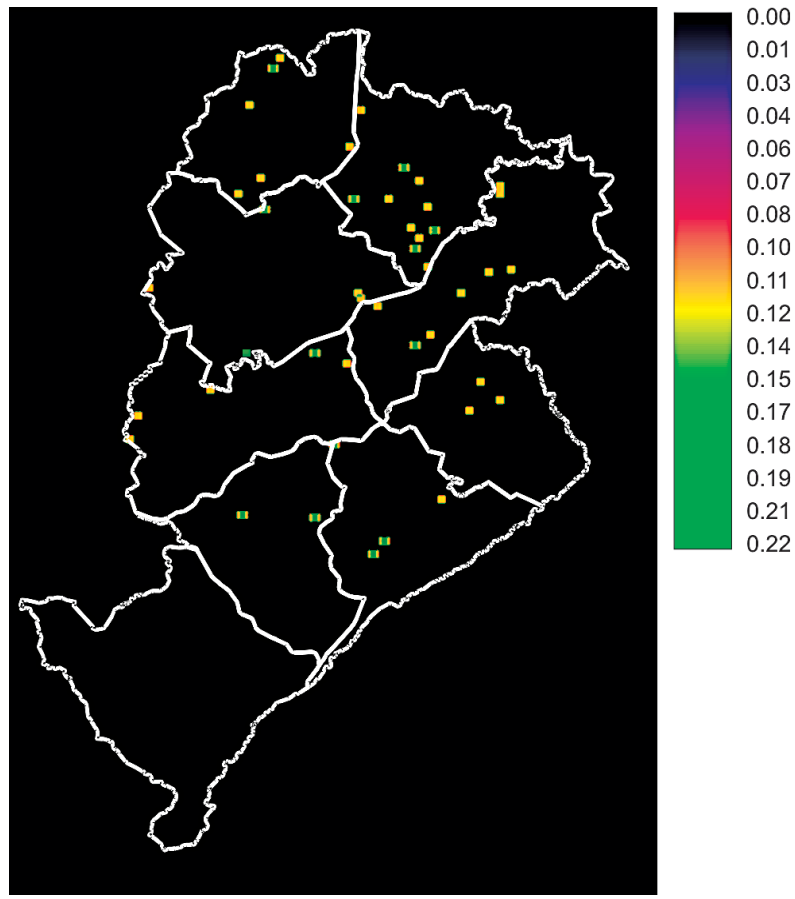

Fig. 4: average of human visceral leishmaniasis cases between April 2001 and March 2002 in Belo Horizonte, obtained by the filter of mobile average $(3 \times 3$ pixels $)$ of the software IDRISI32.

we have observed a correlation between occurrences of human cases in canine leishmaniasis foci (Fig. 5). In percentage terms, $84 \%$ of human leishmaniasis cases are correlated with canine cases.

Canine and human leishmaniasis X biogeography Areas of poverty concentration, in the city of Belo Horizonte, have influenced the emergence of 11.3 and $33.3 \%$ out of the total number of canine and human leishmaniasis cases, respectively. In the areas under vegetation influence, rates of 7.3 and $3.5 \%$ out of the total number of canine and human leishmaniasis cases were observed, respectively. Concerning the influence of hydrographic characteristics in the city of Belo Horizonte, rates of 10.3 and $14 \%$ of canine and human leishmaniasis cases, respectively, has shown to be influenced by this variable. Most of the residences, in which leishmaniasis-infected dogs are located, are between 680 and $980 \mathrm{~m}$ high (Fig. 6). The highest number of canine cases and, human cases were concentrated at altitudes ranging from 780 and 880 m (Fig. 6).

Canine and human leishmaniasis X vectors - Most of canine and human leishmaniasis cases are located in the north of the city of Belo Horizonte. Many leishmaniasis cases are correlated with areas of high density and activity of the species L. longipalpis. Northeast, Northwest, North, Pampulha, and Venda Nova regions showed a high a number of human cases. Regarding canine leishmaniasis cases, those regions showed the following numbers, respectively: 1006, 482, 941, 340, and 607. The regions mentioned above showed high density of L. longipalpis, except for the regions Northeast and North, where only a 


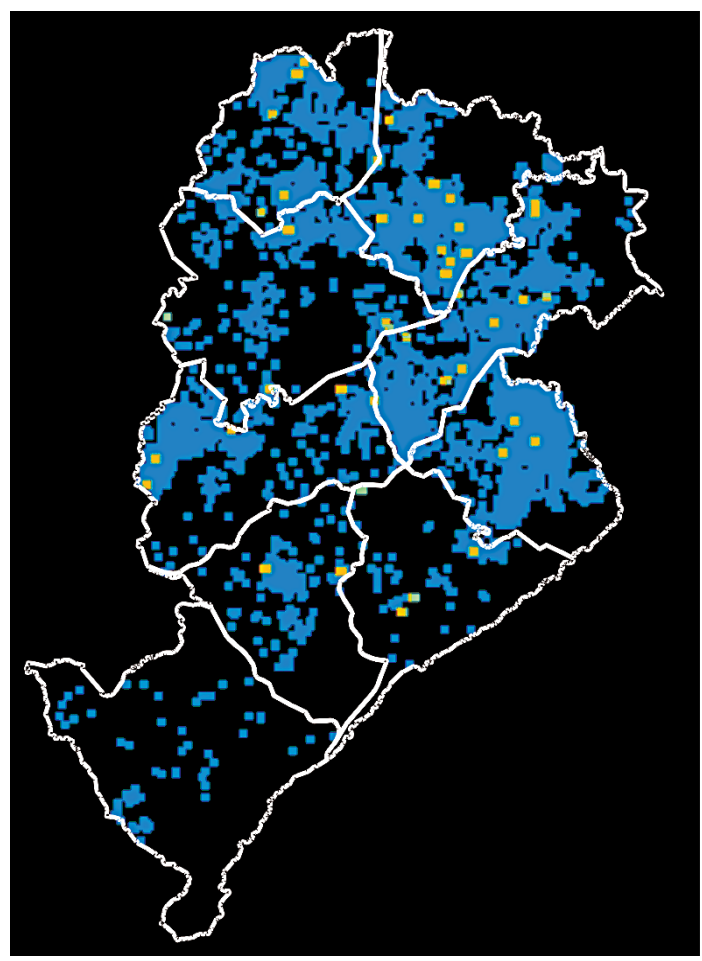

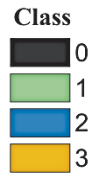

Fig. 5: canine and human leishmaniasis cases between April 2001 and March 2002 in Belo Horizonte, jointly in pixels of $100 \times 100$ $\mathrm{m}$. Class 0: absence of canine and human leishmaniasis cases; class 1: absence of canine leishmaniasis cases and presence of human cases; class 2: presence of canine leishmaniasis cases and absence of human cases; class 3: presence of canine and human leishmaniasis cases.

(A)

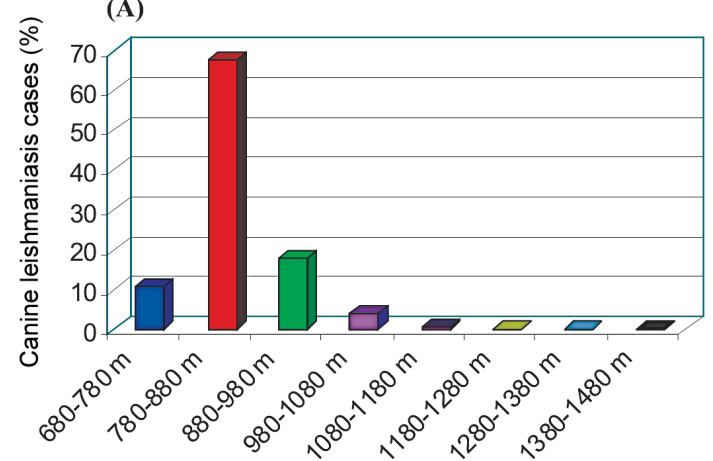

(B)

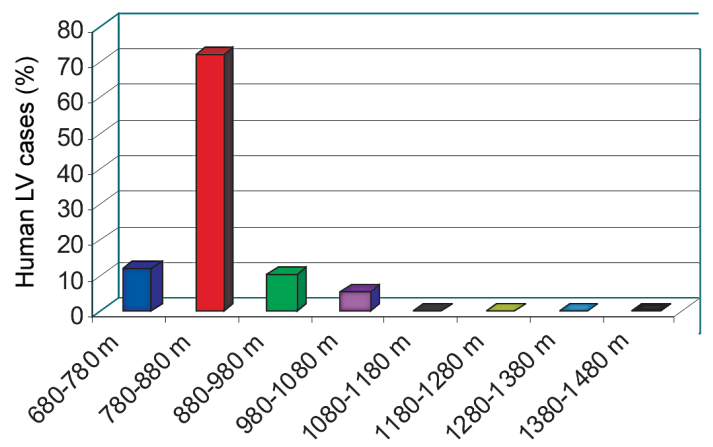

Fig. 6: percentages of influence of altitudes of the city of Belo Horizonte in average total of canine leishmaniasis cases (A) and visceral leishmaniasis human cases (B). number of 11 and 15 specimens, respectively, were collected (Figs 7, 8).

The East region showed 972 canine leishmaniasis cases while the West showed 186 canine cases. In both regions, a great number of insect vectors were captured; however, a low number of human cases were recorded (Figs 7, 8). The Center-South region showed few human and canine leishmaniasis cases (73), and also a low density of L. longipalpis (5 specimens were collected) (Figs $7,8)$. Barreiro, on the other hand, showed no human leishmaniasis cases and the number 66 dogs were diagnosed with the disease. Only three specimens of L. longipalpis were captured throughout a one-year study (Figs 7, 8).

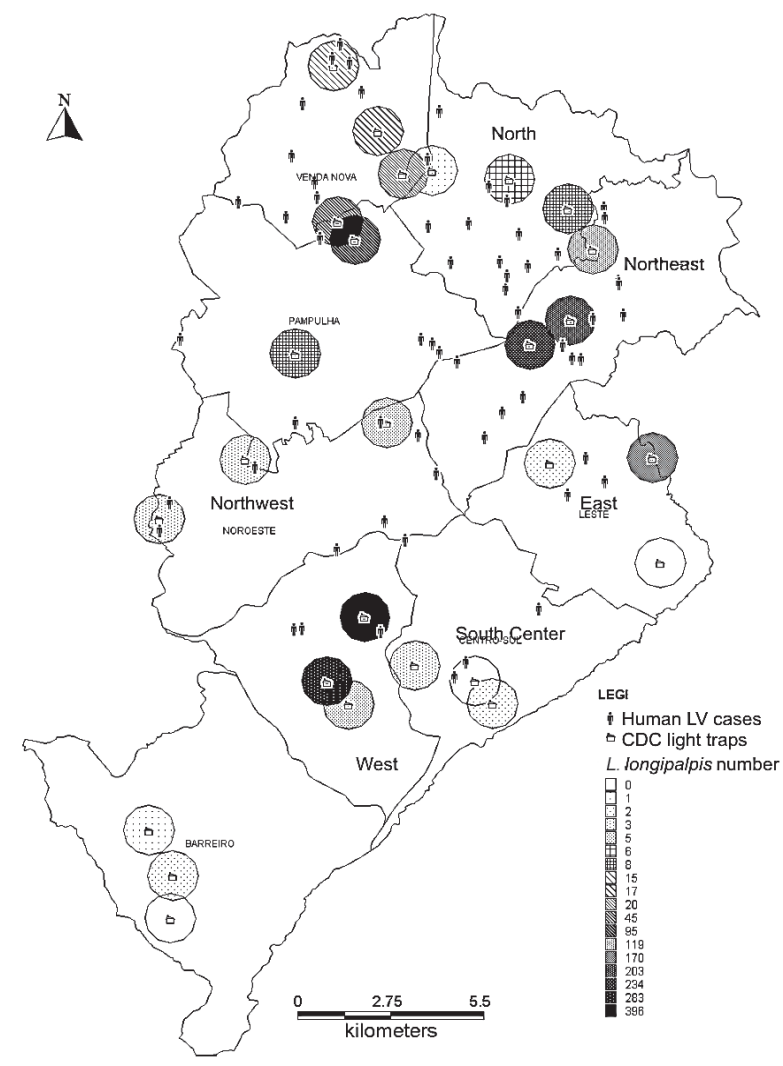

Fig. 7: georefering and analysis of the amount of Lutzomyia longipalpis collected in Belo Horizonte with the CDC trap, between April 2001 and March 2002, and visceral leishmaniasis human cases reported during the same period.

\section{DISCUSSION}

Considering the extensive data set on health, which is collected by means of a geographical reference, geocomputational methods have shown an increasing potential for information analysis that requires a comprehension of spatial distributions (Medronho 1995, Thomson \& Connor 2000, Câmara \& Monteiro 2001). This technique shows several advantages not only for detection and data analysis but also for visual presentation of clusters (Rothman 1990).

One of the research degrees of geoprocessing techniques seeks to identify spatial and temporal trends based on spatial data. Based on this information, environmental 


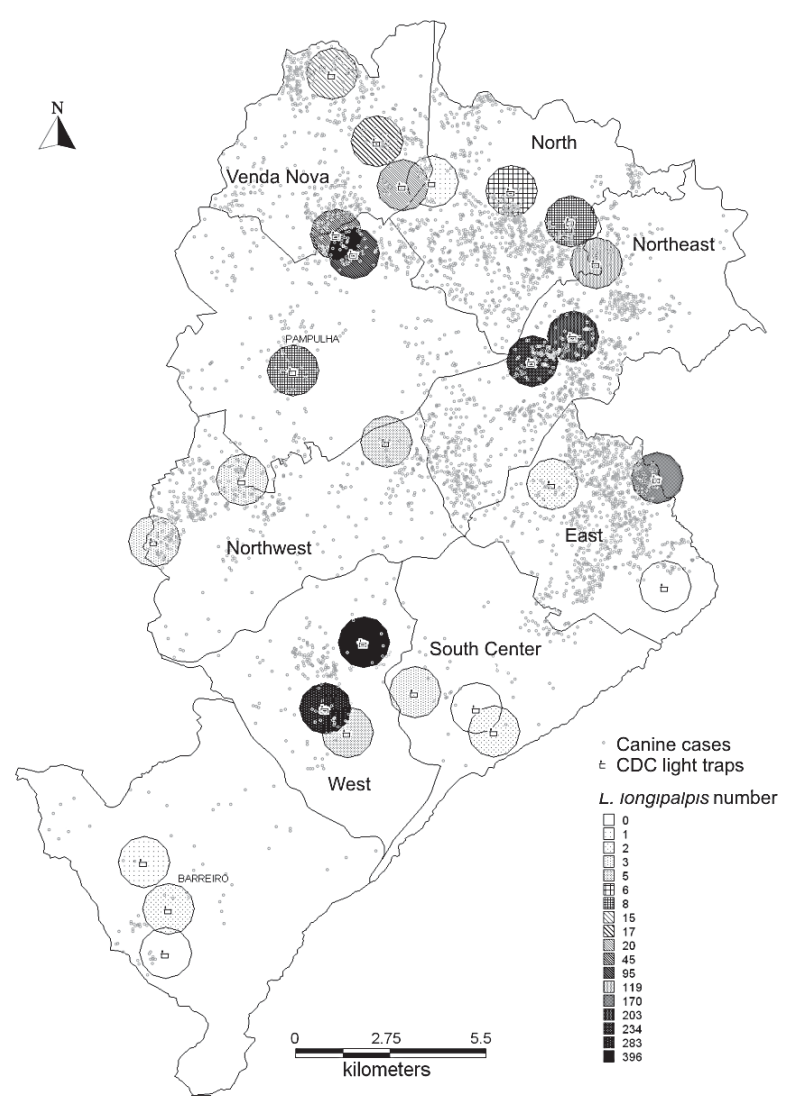

Fig. 8: georefering and analysis of the amount of Lutzomyia longipalpis collected in Belo Horizonte with the CDC trap, between April 2001 and March 2002, and canine leishmaniasis cases reported during the same period.

barriers or vulnerabilities, that allow the spread of diseases in space, may be identified (Barcellos \& Bastos 1996). However, georeference of tabular data is still one of the limiting factors to a widespread use of SGIs in the field of health, when microareas are being analyzed, to which the address of the event is fundamental. The main Information Systems on Health have no address option to be fulfilled, but only information on the district, area or borough, impairing georeference in local scales. Information processing that involves addresses is always complicated, because detailed maps of street stretches associated with local records are rare, precluding utilization possibilities of SGI georeference functions. Moreover, the address field (when it exists) is of poor quality, containing incomplete addresses, mistyping, and misspelled words (King et al. 2004).

Despite limitations, geoprocessing has been widely used in the area of health, mainly in epidemiological surveys on vectors and parasitic diseases (Thomson \& Connor 2000). Attempts to control leishmaniasis cases and phlebotomine vectors have been made through remote sensing. Models of vector distribution have enabled the creation of preventive strategies (Cross et al. 1996, Hay et al. 1997, Connor et al. 1998, Peterson \& Shaw 2003, King et al. 2004).
The results of the present work show a correlation between distributions of human and canine leishmaniasis cases in the city of Belo Horizonte. Such information is corroborated by data from Oliveira et al. (2001), who have observed that human leishmaniasis cases tend to occur in areas of seropositive dogs. A similar fact has been reported, concerning a spatial analysis of an epidemiological survey of VL in Araçatuba, in the state of São Paulo, between 1998 and 1999. The investigators observed that the disease transmission showed to be non-homogeneous in that borough: human transmission occurred in areas of high prevalence of infected dogs (Camargo-Neves et al. 2001).

Leishmaniases, up to the present moment, are associated with rural areas, shantytowns, and foci of poverty concentration (Cuba-Cuba et al. 1985, Azevedo \& Rangel 1991, Souza et al. 2001). However, in the state of Paraná, Brazil, leishmaniasis prevalence in residents of rural areas (43.9\%) showed to be very close to that of urban areas (40\%) (Lima 2000). Kawa and Sabroza (2002) have shown that the urban movement created necessary conditions for the disease spreading in very well defined foci, where enabled a close contact between susceptible individuals and vectors. By using spatial analysis, Werneck and Maguire (2002) have generated models that showed positive associations between VL occurrence in shantytowns or vegetation areas.

Unlike literature data, the variable "areas of poverty concentration" did not seem to influence concentration and emergence of human and canine leishmaniasis cases in Belo Horizonte. It is believed that the disease may have started to be transmitted in these kinds of environments, once 33\% of human VL cases were recorded in the poorer areas of the municipality. However, the dissemination ease, variability of vectors associated with the presence of the parasite and the host, and the population lack of information are all favorable variables for the spread of the disease. Nowadays, leishmaniases are found in every kind of environments that comprise the city of Belo Horizonte.

Elnaiem et al. (1998), using field data and satellite images of Sudan, observed that $P$. orientalis has been found at altitudes between 300 and $720 \mathrm{~m}$ above the sea level. The presence of the insect was also associated with the type of soil and the temperature in that country. Later, Thomson et al. (1999) showed that the presence of the VL vector in Sudan is associated with high pluviometric levels and the presence of vegetation (mainly two species of native trees), which enable the development of the vector. Based on these outcomes, the investigators created a map of risk of contracting VL in that country, through geoprocessing techniques. Camargo-Neves et al. (2002) used environmental parameters associated with ACL standardized coefficients for the state of São Paulo, Brazil, between 1986 and 1995. Analyses have shown that the incidence of leishmaniasis was significantly associated with the presence of L. migonei in the boroughs, surrounding the geomorphologic region of Planalto Atlântico (Atlantic Plateau), and in regions where dense vegetation predominated.

In the current work, vegetation areas had no influence on cases of canine and human leishmaniasis in Belo 
Horizonte. Nevertheless, some authors state that it is necessary to investigate the kind of vegetation surrounding peridomiciliary areas, and not within the city or country, in order to demonstrate association of vectors and leishmaniasis cases with vegetation (King et al. 2004), a fact that was not taken into account in the present study.

When the variable "altitude" was analyzed, it was observed that altitudes between 780 and $880 \mathrm{~m}$ above the sea level have shown to be mostly associated with the highest incidences of canine and human leishmaniasis cases in Belo Horizonte. Such result associated with the fact that most of the phlebotomine sand flies captured at the same altitudes lead us to believe that such variable should be influencing the emergence of new leishmaniasis cases in the municipality.

The variable "altitude" has shown to influence phlebotomine fauna, depending on the ecological context of the city or country. Ferreira et al. (2001) have studied a phlebotomine fauna in peridomiciliary areas at different altitudes (650-750 m, 750-850 $\mathrm{m}$ and 850-950 $\mathrm{m}$ above the sea level) in the borough Afonso Cláudio, state of Espírito Santo, Brazil. Most insect vectors of ACL (L. intermedia, L. whitmani, L. migonei) were captured at altitudes between 650-750 m. At higher altitudes the number of insects collected was lower. It was also observed that the number of human leishmaniasis cases decreased with higher altitudes.

Using spatial analysis, Elnaiem et al. (2003) observed that VL human cases have a distribution in regions along the rivers that cross Sudan. Low altitudes (between 400$450 \mathrm{~m}$ ) and high pluviometric rates enable the increase of leishmaniasis cases in the country.

King et al. (2004) have remarked that the ACL cases are heterogeneously distributed in Colombia as a whole, but there is no transmission along the Andes, due to high altitudes.

Our work has not provided further information regarding the vector distribution and its correlation with human leishmaniasis cases. Human and canine leishmaniasis cases were recorded in domiciliary and peridomiciliary areas of phlebotomine capture. However, some issues have been raised such as how human and canine leishmaniasis cases have been taking place in the North region of Belo Horizonte? All phlebotomine collection sites showed to have a prevalence of the following species: L. whitmani, L. pessoai, and L. intermedia, which are all ACL vectors, summing up 181 specimens. Only 15 specimens of $L$. longipalpis were captured in the same locality. In the Northwest region, although a very low number of phlebotomine sand flies have been captured, the number of human and canine leishmaniasis cases is very high.

Lainson and Rangel (2003) consider the possibility of a different species, particularly L. intermedia, could be a VL transmitter in specific regions. This species shares a similar habitat to that of L. longipalpis, which is highly anthropophilic and feeds itself on dogs. Such features are discussed in the present investigation, supporting the possibility of this species as a VL vector, a fact that would lead to some non-responded questions.

A phlebotomine sand fly capture in other sites of the city as well as georeference of canine and human leishma- niasis cases previous to and after 2001 would also provide important data for the problem resolution and for studies on ecology of leishmaniases in Belo Horizonte.

In general, a large number of phlebotomine sand flies were observed in the regions associated with many cases of canine and human leishmaniasis cases. The East, Northeast, Northwest, North, West, Pampulha, and Venda Nova regions should be given priority in leishmaniasis control measures due to the high number of phlebotomine sand flies collected and the large number of dogs and people infected and recorded in those areas.

Belo Horizonte is divided into regions. Such regions work independently in the control of several epidemics. However, this division does not represent barriers to the phlebotomine vectors. They seek the most adequate conditions regarding climate, reproduction sites, and food sources, regardless administrative areas established by man. Therefore, we suggest that more efficient control measures are implemented, establishing action plans that give priority to the regions at altitudes between 780 and $880 \mathrm{~m}$ and canine leishmaniasis foci. This strategy should involve all regions surrounding the disease foci without the barrier of "administrative areas."

\section{ACKNOWLEDGEMENTS}

To the clerks of MSHBH for collaborating with sand flies collection; to Marcelo Rezende de Freitas (Funasa) for lending the traps; to the colleagues of the Laboratory of Cartography of UFMG.

\section{REFERENCES}

Albuquerque MFPM 1993. Urbanização, favelas e endemias: a produção da filariose no Recife, Brasil. Cad Saúde Pública 9: 487-497.

Azevedo ACR, Rangel EF 1991. A study of sandfly species (Diptera: Psychodidae: Phlebotominae) in a focus of cutaneous leishmaniasis in the municipality of Baturité, Ceara State, Brazil. Mem Inst Oswaldo Cruz 88: 509-512.

Barcellos C, Bastos FI 1996. Geoprocessamento, ambiente e saúde: uma união possível? Cad Saúde Pública 12: 389397.

Câmara G, Monteiro AMV 2001. Geocomputation techiniques for spatial analysis: are they relevant to health data? Cad Saúde Pública 17: 1059-1081.

Camargo-Neves VLF, Gomes AC, Antunes JLF 2002. Correlação da presença de espécies de flebotomíneos (Diptera: Psychodidae) com registros de casos da leishmaniose tegumentar americana no Estado de São Paulo, Brasil. Rev Soc Bras Med Trop 35: 299-306.

Camargo-Neves VLF, Katz G, Rodas LAC, Poletto DW, Lage LC, Spínola RMF, Cruz OG 2001. Utilização de ferramentas de análise espacial na vigilância epidemiológica de leishmaniose visceral americana - Araçatuba, São Paulo, Brasil, 1998-1999. Cad Saúde Pública 17: 1263-1267.

Connor SJ, Thomson MC, Flasse SP, Perryman AH 1998. Environmental information systems in malaria risk mapping and epidemic forecasting. Disasters 22: 39-56.

Cross ER, Newcomb WW, Turcker CJ 1996. Use of weather data and remote sensing to predict the geographic and seasonal distribuition of Phlebotomus papatasi in Southwest Asia. Am J Trop Med Hyg 54: 530-536. 
Cuba-Cuba CA, Miles MA, Vexenat A, Barker DC, Mc Mahon Pratt D, Butcher J, Barreto AC, Marsden PH 1985. A focus of mucocutaneous leishmaniasis in Três Braços, Bahia, Brazil: characterization and identification of Leishmania stocks isolated from man and dogs. Trans R Soc Trop Med Hyg 79: 500-507.

Elnaiem DEA, Connor SJ, Thomson MC, Hassan MM, Hassan HK, Aboud MA, Ashford RW 1998. Environmental determinants of the distribuition of Phlebotomus orientalis in Sudan. Ann Trop Med Parasitol 92: 877-887.

Elnaiem DEA, Schorscher J, Bendall A, Obsomer V, Osman ME, Mekkawi AM, Connor SJ, Ashford RW, Thomson MC 2003. Risk mapping of visceral leishmaniasis: the role of local variation in rainfall and altitude on the presence and incidence of kala-azar in Eastern Sudan. Am J Trop Med Hyg 68: 10-17.

Ferreira AL, Sessa PA, Varejão JBM, Falqueto A 2001. Distribuition of sand flies (Diptera: Psychodidae) at different altitudes in an endemic region of American cutaneous leishmaniasis in the state of Espírito Santo, Brazil. Mem Inst Oswaldo Cruz 96: 1061-1067.

Figueiredo CM, Mourão AC, de Oliveira MAA, Alves WR, Ooteman MC, Chamone CB, Koury MC 2001. Leptospirose humana no município de Belo Horizonte, Minas Gerais, Brasil: uma abordagem geográfica. Rev Soc Bras Med Trop 34: 331-338.

Hay SI, Tucker CJ, Rogers DJ, Packer MJ 1997. Remotely sensed surrogates of meteorological data for the study of the distribuition and abundance of arthropod vectors of disease. Ann Trop Med Parasitol 90: 1-19.

Kawa H, Sabroza PC 2002. Espacialização da leishmaniose tegumentar na cidade do Rio de Janeiro. Cad Saúde Pública 18: 853-65.

King RJ, Campbell-Lendrum DH, Daviest CR 2004. Predicting geographic variation in cutaneous leishmaniasis, Colombia. Emerg Infect Dis 4: 598-607.

Lainson R, Rangel EF R 2003. Lutzomyia longipalpis e a ecoepidemiologia da leishmaniose visceral americana (LVA) no Brasil. In EF Rangel, R Lainson (eds), Flebotomineos do Brasil, Fiocruz, Rio de Janeiro, p. 311-336.

Lima AP 2000. Distribuição da Leishmaniose Tegumentar e Análise da sua Ocorrência em Ambientes Antrópicos no Estado do Paraná. Brasil, MSc Thesis, Centro de Ciências da Saúde, Universidade Estadual de Londrina, Paraná, 65 pp.

Medronho RA 1995. Geoprocessamento e Saúde: uma Nova Abordagem do Espaço no Processo Saúde-Doença, Fiocruz/ Cict/Nect, Rio de Janeiro, $135 \mathrm{pp}$.

Oliveira CDL, Assunção RM, Reis IA, Proietti FA 2001. Spatial distribuition of human and canine visceral leishmaniasis in Belo Horizonte, Minas Gerais state, Brazil, 1994-1997. Cad Saúde Pública 17: 1231-1239.

Peterson AT, Shaw J 2003. Lutzomyia vector for cutaneous leishmaniasis in Southern Brazil: ecological niche models, predicted geographic distribuitions, and climate change effects. Inter J Parasitol 33: 919-931.

Pina MF 1994. Modelagem e Estruturação de Dados Não Gráficos em Ambiente de Sistemas de Informação Geográfica: Estudo de Caso na Área de Saúde Pública, MSc Thesis, IME, Rio de Janeiro.

Prefeitura Municipal de Belo Horizonte 1995. Plano Diretor de Belo Horizonte: lei do uso do solo, estudos básicos, Minas Gerais.

Rothman, KJ 1990. Introdução ao geoprocessamento. In Simpósio Brasileiro de Geoprocessamento, Sagres, São Paulo.

Sabroza PC, Toledo LM, Osanai CH 1992. A organização do espaço e os processos endêmicos-epidêmicos. In MC Leal, PC Sabroza, RH Rodrigues, PM Buss (orgs), Saúde. Ambiente e Desenvolvimento, Vol. II, Abrasco, Rio de Janeiro, Hucitec, São Paulo, p. 57-77.

Silva JX, Saito CH, Braga Filho JR, Oliveira OM, Pinheiro NF 1991. Um banco de dados ambientais para a Amazônia. Rev Bras Geo 3: 125-132.

Souza CM, Pessanha JE, Barata RA, Monteiro EM, Costa DC, Dias ES 2004. Study on phlebotomine sand fly (Diptera: Psichodidae) fauna in Belo Horizonte, state of Minas Gerais. Mem Inst Oswaldo Cruz 99: 795-803.

Souza NA, Andrade-Coelho CA,Vilela ML, Rangel EF 2001. The phlebotominae sand fly (Diptera: Psychodidae) fauna of two Atlantic rain forest reserves in the state of Rio de Janeiro, Brazil. Mem Inst Oswaldo Cruz 96: 319-324.

Sudia WA, Chamberlain RW 1962. Battery-operated light trap: an improved model. Mosq News 22: 126-129.

Thomson MC, Connor SJ 2000. Enviroment information systems for the control of arthropod vectors of disease. Med Vet Entomol 14: 227-244.

Thomson MC, Elnaiem DA, Ashford RW, Connor SJ 1999. Toward a dala azar risk map for Sudan: mapping the potential distribuition of Phlebotomus orientalis using digital data of environmental variables. Trop Med Inter Health 4: 105113.

Werneck GL, Maguire JH 2002. Spatial modeling using mixed models: an ecologic study of visceral leishmaniasis in Terezina, Piauí state, Brasil. Cad Saúde Pública 18: 633637.

Young DG, Duncan MA 1994. Guide to the identification and geographic distribution of Lutzomyia sand flies in Mexico, the West Indies, Central and South America (Diptera, Psychodidae). Mem Am Entomol Inst 54: 1-881. 